Andrew Goatly*

\title{
Ecology, physics, process philosophies, Buddhism, Daoism, and language: A case study of William Golding's The Inheritors and Pincher Martin
}

https://doi.org/10.1515/jwl-2021-0002

Received June 10, 2020; accepted January 28, 2021; published online July 28, 2021

\begin{abstract}
Much has been written about the ecological perspectives of Buddhism and Daoism, as examples of philosophies which emphasize process, impermanence, interconnectedness, and compassion for nature. And the interconnectedness of the various elements of the biosphere and the Earth's crust is the basis of ecological Gaia theory. Some physicists and process philosophers have drawn attention to the inadequacies of European languages to represent the world of quantum reality, radical undifferentiated wholeness and interconnectedness, and the dynamism and uncontrollability of the material world. Notable among these were physicists David Bohm and David Peat, who looked to Blackfoot, an Algonquin language of North America, for a better representation of the natural world as interacting processes.

This article explores some of the commonalities between Buddhism/Daoism, process philosophies, modern physics and ecological theory. It then addresses the question of the affordances different languages and grammars provide for a deep ecological representation in tune with quantum physics and Buddhism/Daoism. The climax of the article starts with the work of Michael Halliday on the local grammar of William Golding's The Inheritors (Golding, William. 1961 [1955]. The Inheritors. London: Faber), and performs a similar grammatical analysis of two passages from Golding's later work Pincher Martin (Golding, William. 1956. Pincher Martin. London: Faber). It concludes that the Neanderthal mind style and life style in The Inheritors and the world of the drowning Pincher Martin are represented in a grammatical style more appropriate for a Buddhist/Daoist/quantum physics/deep ecological worldview of human interaction with the natural world.
\end{abstract}

Keywords: Buddhism; Daoism; systemic functional grammar; William Golding

\footnotetext{
*Corresponding author: Andrew Goatly, Department of English, Lingnan University, Hong Kong, China, E-mail: apgoatly@gmail.com
} 


\section{Introduction}

This paper is organized as follows. I begin by exploring the commonalities of modern physics, ecology, and Buddhism/Daoism (the horizontal line in Figure 1), most notably their emphasis on dynamic interrelated process, and their rejection of human domination of nature. I proceed to delineate the inadequacies of English grammar for representing process and non-domination of nature and how nominalization and other languages might mitigate this (the other two lines in Figure 1). Then, building on Michael Halliday's analysis of William Golding's The Inheritors (Golding 1961 [1955]), I perform a similar grammatical analysis of another Golding novel Pincher Martin (Golding 1956). I show how contrasting patterns of transitivity in the two novels illustrate different perspectives, one opposed to the ideology of modern science, ecology, Buddhism/Daoism, and the other more in tune with it.

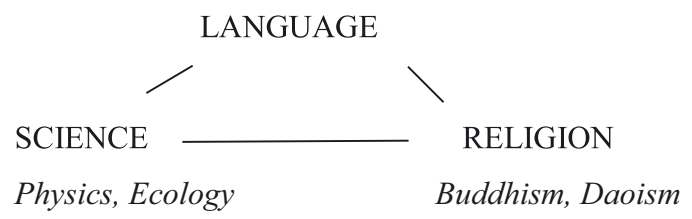

Figure 1: Outline of the paper.

\section{Quantum physics, ecological theory (Gaia theory), and Buddhism/Daoism}

This section examines the commonalities between theories of the physical universe, namely quantum physics and Gaia theory, and religious philosophies, Buddhism and Daoism. It discusses four commonalities: the emphasis on impermanence and process, the dynamism of the universe, the interrelatedness of all parts of the physical universe, and the spontaneity and dynamism of nature which defies human control.

\subsection{Impermanence and process}

Both quantum physics and Buddhism/Daoism stress that the material world that we regard as populated by permanent "things" is in fact transitory and always in the flux of change, movement and process. As the physicist David Bohm pointed out:

Indeed it is not possible in relativity to obtain a consistent definition of an extended rigid body, because this would imply signals faster than light [...]. Actually, relativity implies that 
neither the point particles nor the quasi-rigid body can be taken as primary concepts. Rather these have to be expressed in terms of events and processes. (Bohm 1980: 123-124)

He invites us to consider a stream with its whirlpools as a metaphor for this impermanence:

The best image of process is perhaps that of the flowing stream whose substance is never the same. On this stream one may see an ever-changing pattern of vortices [...] which evidently have no independent existence as such. Rather they are abstracted from the flowing movement, arising and vanishing in the total process of the flow. (Bohm 1980: 48)

Similarly Buddhism stresses the fact that "things" and our selves have only an illusory permanence.

By ignorance the being fails to view the true impermanent and substanceless nature of existence. He relishes the things of the world, taking them to be real and lasting and creates a craving for them. (Kashyap 1954: 212)

In short, impermanence is a synonym for arising and passing away, or birth and destruction. (Kalupahana 1975: 84)

This truth is expressed by the Buddhist doctrine of wuchang (无常, 'anitya'). And this is echoed in Daoism:

Finally the $\mathrm{Dao}^{1}$ is understood as the universe as cosmological process, specifically as expressed in the constant patterns of oscillation between yin and yang. In this sense the Dao is the universe, but it is a universe of constant change and transformation. (Komjathy 2014: 98)

\subsection{Dynamism}

The world of things is impermanent because the ultimate reality is dynamic process. This inherent dynamism acknowledges that things, including the apparently inanimate ones are far from passive, but in fact energetic interactions. Capra is worth quoting on this because he integrates the worldview of quantum physics with Daoism in his book The Tao of physics: A exploration of the parallels between modern physics (Capra 1982). He starts with a scientific perspective, emphasizing the dynamic processes constituting the physical universe:

1 Some authors use the words Dao/Daoism and others Tao/Taoism. These are interchangeable and refer to the same concept/philosophy. 
All the material objects in our environment are made up of atoms which link up with each other in various ways to form an enormous variety of molecular structures which are not rigid and motionless, but oscillate according to their temperature and in harmony with the thermal vibrations of their environment. In the vibrating atoms, the electrons are bound to the atomic nuclei by electric forces that try to keep them as close as possible, and they respond to this confinement by whirling around extremely fast. In the nuclei, finally, the protons and neutrons are pressed into a minute volume by the strong nuclear forces, and consequently race about with unimaginable velocities. (Capra 1982: 215-216)

And he continues by linking this dynamism with the mysticism of Eastern religions, notably Daoism:

Modern physics, then, pictures matter not at all as passive and inert, but as being in a continuous dancing and vibrating motion whose rhythmic patterns are determined by the molecular, atomic and nuclear structures. This is also the way in which the eastern mystics see the material world. They all emphasize the universe has to be grasped dynamically, as it moves, vibrates and dances; that nature is not in a static, but in a dynamic equilibrium [...].

Only when there is stillness in movement can the spiritual rhythm appear which pervades heaven and Earth. (Capra 1982: 215-216)

Matter's propensity for spontaneous change is well captured by the following quote:

If the princes and kings can watch over it

The thousands of things will change by themselves.

(Lafargue 1992: 176)

According to Daoism these dynamic patterns of active process proceed according to principles of order.

But beyond this Dao is also order - clearly manifest in the rhythmic changes and patterned processes of the natural world [...]. Its patterns are what the Chinese call "self-so" or "nature", the spontaneous and observable way things are naturally. (Kohn 2009: 23)

\subsection{Interrelatedness}

Order presupposes a web of interrelatedness, which is expressed not only in quantum physics but also James Lovelock's Gaia theory (Lovelock 1988).

Rather, we say that inseparable quantum interconnectedness of the whole universe is the fundamental reality, and that relatively independently behaving parts are merely particular and contingent forms within this whole. (Bohm and Hiley 1975: 101) 
At the atomic level, then, the solid material objects of classical particle physics dissolve into patterns of probabilities [...] of interconnections. (Capra 1982: 150)

David Bohm used the hologram as an analogy for the whole of the universe being enfolded in each of its parts. Each part contains the whole. If any part of the hologram is illuminated the entire image will be reconstructed (Bohm 1980).

Ecology also stresses the web of life, whose strands are all connected. Gaia theory (Lovelock 1988) is the hypothesis that the world, including the atmosphere, the oceans, the biota, the rocks and minerals of the crust, functions as one large self-regulating organism:

Specifically the temperature, oxidation state, acidity, [...] are at any time kept constant, and that this homeostasis is maintained by active feedback processes operated automatically and unconsciously by the biota [...]. Life and its environment are so closely coupled that evolution concerns Gaia, not the organisms or the environment taken separately. (Lovelock 1988: 19)

Though impermanent and dynamic and therefore inherently unstable these processes form persistent patterns. For example, the oxygen and methane in the atmosphere should react in sunlight to produce carbon dioxide and water vapor. But the amounts of methane and oxygen remain more or less constant. The only explanation is the influence of a control system, Gaia, in dynamic equilibrium (Lovelock 1988: 31). I find in this notion of persistent instability echoes of the Daoist view of ordered processes mentioned above, or of what the English poet Shelley, echoing the earlier poet Edmund Spenser's “Mutability Cantos”, termed a world "eterne in mutability".

Weather's role in the homeostasis in dynamic equilibrium of the Gaia organism is observable in the various cycles: water, nitrogen, sulphur. The latter operates as follows (Figure 2). Sulphur is washed by rivers into the sea. Algal seaweed produces dimethyl-sulphide, $\left(\mathrm{CH}_{3}\right)_{2} \mathrm{~S}$. The sulphur element rises into the atmosphere, where it is oxidized into sulphuric acid, $\mathrm{H}_{2} \mathrm{SO}_{4}$. This provides the condensation nuclei, the seeds, for cloud formation and consequently the rain, which then washes it back to Earth. The weather functions as part of a larger organism, of which only one part, the algae, are traditionally viewed as living (Lovelock 1988: 140-145).

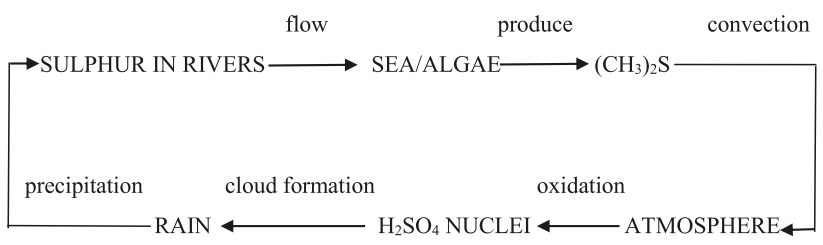

Figure 2: The sulphur cycle. 


\subsection{Contesting human domination of nature}

Already in Daoism's and quantum physics' rejection of the notion of an inanimate nature there is the implication that nature cannot be controlled. Paul Josephson (2002) in his splendidly alarming book, Industrialized nature: Brute-force technology and the transformation of the natural world, shows how attempts to control nature have had disastrous consequences for the world of which we are a part. The book is a historical investigation of the effects of large scale projects using "brute force technology" - the confluence of science, engineering, finance, politics, and arrogance to produce large-scale technological systems to manage natural resources (Figure 3).

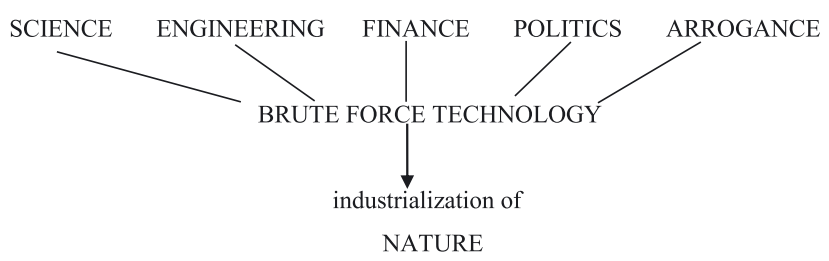

Figure 3: Factors in the industrialization of nature.

In each aspect of the management process growing, harvesting, processing, storing, studying, understanding, buying, selling, importing, exporting, building, excavating, channeling, funneling, bulldozing, exploding, imploding, distributing and consuming we have gained extraordinary power to transform nature into something increasingly orderly, rational, and machine-like - in a word, industrial. (Josephson 2002: 3)

In contrast with these destructive efforts, Daoism propounds the concepts of $w u$-wei (无为) and ziran (自然).

$W u$-wei is effortless activity, the practice of not doing anything extra or unnecessary; conservation and non-attachment, "non-interference" as letting be, as allowing space for existential freedom. It involves allowing each being to unfold according to its own nature and connection with the Dao, allowing space for ziran ('suchness, being-so-in-itself') to appear. (Komjathy 2014: 84-85)

In the chapter Supreme Happiness (section 18) of Chuang Tzu: Basic writings, this concept is explained:

The inaction of Heaven is its purity, the inaction of earth is its peace. So the two inactions combine and all things are transformed and brought to birth. Wonderfully, mysteriously, there is no place they come out of. Mysteriously, wonderfully, they have no sign. Each thing 
minds its business and all grow up out of inaction. So I say, Heaven and earth do nothing and there is nothing that is not done. (Chuang Tzu 1964: 112-113)

It may be of interest to relate the Daoist concept of ziran to the medieval philosopher Duns Scotus' concept of haeccitas ('suchness, individuation'). The concept is probably most often encountered in the writings and poetry of Gerard Manley Hopkins, the Christian Jesuit priest, who developed it into the theory of inscape and instress.

[Hopkins] felt that everything in the universe was characterized by what he called inscape, the distinctive design that constitutes individual identity. This identity is not static but dynamic. Each being in the universe "selves", that is, enacts its identity. And the human being, the most highly selved, the most individually distinctive being in the universe, recognizes the inscape of other beings in an act that Hopkins calls instress, the apprehension of an object in an intense thrust of energy toward it that enables one to realize specific distinctiveness. Ultimately, the instress of inscape leads one to Christ, for the individual identity of any object is the stamp of divine creation on it. (Greenblatt and Abrams 2006: 1,513-1,514)

We note how these concepts share with Daoism the emphasis on dynamism, the enactment of identity, and its relation to creative forces, though in this case Christ's divine creation rather than the Dao/Tao. However, Hopkins' emphasis on the response, instress, is apparently rather more energetic than wu-wei, which merely allows space for the unfolding of ziran.

Planned deliberate action to dominate nature is incompatible with wu-wei, or instress for that matter, which is an aesthetic cum emotional response to sensed phenomena.

In such a state [wu-wei] all human actions become as spontaneous and mindless as those of the natural world. Man becomes one with Nature or Heaven, as Chuang Tzu calls it, and merges himself with Tao, or the Way, the underlying unity that embraces man, Nature, and all that is in the universe. (Chuang Tzu 1964: 6)

Attempts to dominate and industrialize nature are doomed to be destructive failures, as the Tao Te Ching puts it:

Those who would take over the Earth

And shape it to their will

Never, I notice, succeed.

One who works, ruins,

One who grasps loses.

(Lafargue 1992: 134) 


\section{Problems with language}

My contention is that the worldview shared by these philosophies and quantum physics is difficult to express in many languages and in their discoursal uses, because of their unmarked grammatical patterns. Indeed, both modern quantum physics and Buddhism and Daoism are suspicious of language, and this section examines why and how this might be remedied, drastically by using a process-oriented language like Blackfoot, and less radically by employing nominalization within English.

\subsection{Physics, ecology, and language}

I have dealt at great length elsewhere (Goatly 2007) with the problems of the grammar of Standard Average European (SAE) languages in representing or constructing a worldview compatible with that of the material universe as interrelated dynamic process with its recognition of the futility of attempts to dominate nature, as sketched above. In brief, the problems are that this grammar constructs human activity within a canonical event model (Figure 4). This model sees human action by an agent (subject noun phrase) carrying out a process (the verb phrase, the line with arrow) on a patient (object noun phrase) to bring about changes to it (the squiggly line). This unidirectional action by an agent on a supposedly inert patient takes place within a setting, locational or temporal. The main problems with this model and its grammatical correlates are:

(1) the distinction between nouns and verbs when nouns actually refer to processes too;

(2) setting separated from process;

(3) a suggestion that human actors can dominate nature.

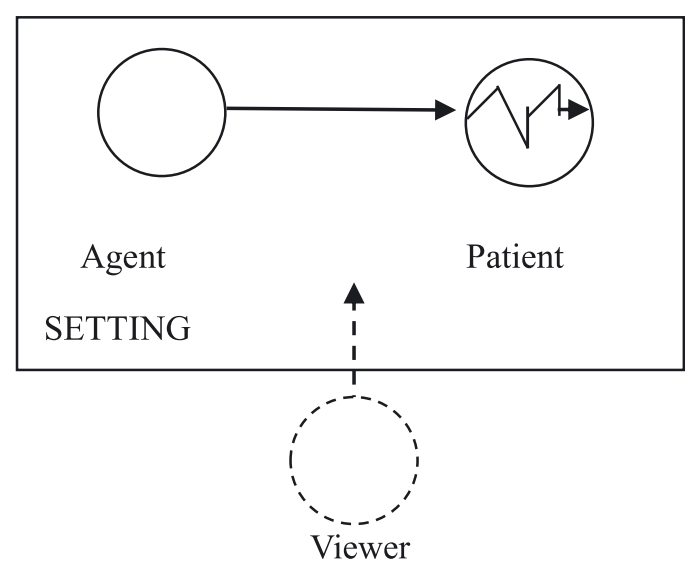

Figure 4: The canonical event model (after Langacker 1991). 
Take for example the sentence:

Marksmen are shooting deer in many city parks and nature areas.

Parks, nature areas, and marksmen represented as things (nouns) not processes. City parks and nature areas are represented as a peripheral setting for the process, a location circumstance, and unaffected by it, though the vegetation and soil of these areas will undoubtedly be affected by the death of the deer. Humans are the voluntary agents and non-humans are the inert affected patients. In fact, as I have discussed, reality according to modern science/Buddhism/Daoism is interrelated processes which make a dynamic whole, and non-human and inanimate "things" have an energy and dynamism of their own.

\subsection{Process, interrelatedness, and overcoming problems with grammar}

SAE languages need critiquing for the way they construct a commonsense model out of step with physical and ecological reality. An interesting figure in this regard is David Bohm, the physicist, lamenting these problems with language and the inadequacy of English for conveying the process nature of quantum reality. He attempted to invent a language called the "rheomode" to address this inadequacy. However, shortly before his death he met several Algonquin speakers in North America/Dakota. David Peat, another physicist, related how this encounter led to Bohm's realization: "What to Bohm had been a major breakthrough in human thought - quantum theory, relativity, his implicate [holographic] order [...] - were part of the everyday life and speech of the Blackfoot [...]" (Peat 1996: 237-238 cited in Goatly 2007: 316).

Peat goes on to demonstrate the primacy of process in physics and how this is reflected in the centrality of verbs and marginalization of nouns in Blackfoot grammar:

In modern physics the essential stuff of the universe cannot be reduced to billiard-ball atoms, but exists as relationships and fluctuations at the boundary of what we call matter and energy. Indigenous [Blackfoot] science teaches that all that exists is an expression of relationships, alliances, and balances between energies, powers or spirits. (Peat 1996: 7 cited in Goatly 2007: 315)

Sa'ke'j Henderson [a Blackfoot speaker] has said that he can go for a whole day without ever speaking a noun, just dealing in the rhythms and vibrations of process. Nouns do exist [...] but, like the vortex that forms in a fast flowing river, [...] are temporary aspects of the everflowing process. (Peat 1996: 237 cited in Goatly 2007: 316) 


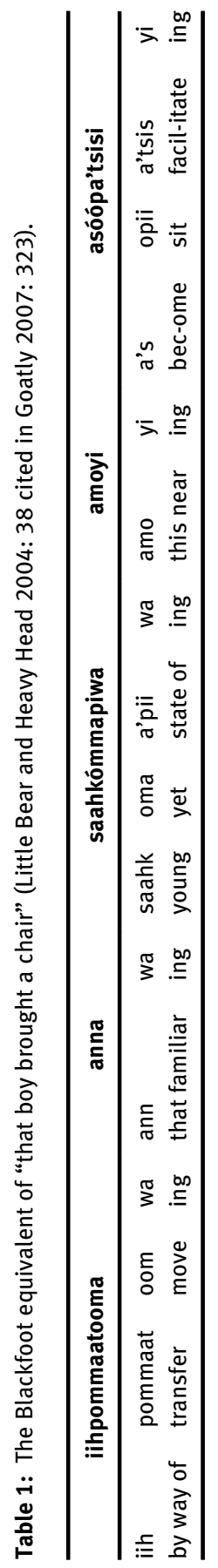


Verbs, therefore dominate the grammar of the Algonquin peoples, because, they "are concerned with the animation of all things within their process-vision of the cosmos" (Peat 1996: 222 cited in Goatly 2007: 316). Consider, for instance, the Blackfoot sentence, equivalent to the English "the boy brought a chair" (Table 1).

Here we have the interaction of three or four processes, transfer/moving, being young, facilitating sitting, rather than the canonical event version where an agent, the boy, moves the patient, the chair.

By contrast with Blackfoot, resources of English grammar to undermine the canonical event model are somewhat limited (Goatly 2007). But, for the purposes of this article, it is worth singling out nominalization as one such resource. It pushes us towards a model more consistent with the physics/Gaia/Buddhist/ Daoist worldview sketched in Section 2 above. As follows:

(1) Nominalization may blur the boundary between things and processes: if, in the case of nominalizations, nouns can realize processes, can all nouns really refer to processes?

(2) Nominalization can exclude any reference to things, either a patient or a causal agent external to the process, so highlighting this process and suggesting it is selfgenerated. Consider this example from Wikipedia: "Condensation commonly occurs when a vapor is cooled and/or compressed to its saturation limit when the molecular density in the gas phase reaches its maximal threshold". ${ }^{2}$ Instead of saying the vapor condenses, or X condenses the vapor, we have "condensation occurs", not mentioning a thing that condenses or things that caused the condensation, though this may be inferred from later in the sentence.

(3) When nominalizations are both subject and object of a clause they represent the interaction of two processes. This example is from a history textbook: "Competition for individual wealth stimulated the growth of trade" (Eggins et al. 1993: 90). Or, take my own example, “[Economic] growth causes [environmental] pollution”.

The increasing use of nominalization in modern scientific texts (Halliday 1993) might relate to the primacy of process.

\subsection{Buddhism/Daoism and language}

Buddhism and Daoism also recognize problems with language. Firstly, language is inadequate for expressing truths (paradoxical though this statement may be!).

2 https://en.wikipedia.org/wiki/Condensation (accessed 12 August 2020). 
"The Dao that can be expressed is not the eternal Dao" is the opening line of the Tao Te Ching. "Daoists have traditionally described the Dao (Tao; Way), the sacred or ultimate concern of Daoists, as [...] nameless, numinous, and unknowable [...] beyond language and conception” (Komjathy 2014: 2).

One particular problem seems to be differentiation and classification:

What the Eastern mystics are concerned with is a direct experience of reality which transcends not only intellectual thinking but also sensory perception [...]. Knowledge that comes from such an experience is called "absolute knowledge” by Buddhists because it does not rely on the discrimination, abstractions and classifications of the intellect [...]. It can never be adequately described by words, because it lies beyond the realms of the senses and the intellect from which our words and concepts are derived [...]. (Capra 1982: 36-37)

The follower of the Dao/Buddhist should: avoid illusions arising from differentiation and ordinary unreal categories, reach a state of universal mind above limitations of existence or differentiation, or a Buddha's universal and impartial perception, his absolute intuition above the laws of differentiation; become "ignorant" or transcend perception, thereby attaining ultimate wisdom independent of differentiation.

Language mandates intellectual processes differentiating aspects of the dynamic whole into discrete categories, denying ziran or individuation by insisting on classification and the perceptions, which in turn are often guided by the linguistic classification systems which privilege one aspect of a phenomenon over others. In this respect Buddhism and Daoism are more radical in their approach to language than the physicists Bohm and Peat, because these religious philosophies regard all language as ultimately distorting and fostering illusion.

\section{Summary of commonalities between science and religion}

To summarize, we have seen that Buddhism/Daoism and ecology/modern physics insist on:

- Nature as process

- Nature as dynamic and ultimately uncontrollable (by humans)

- Nature as an interrelated whole

- Languages like English as generally inadequate for the description of reality

- This inadequacy being addressed by emphasizing process, either less or more radically, through

- Nominalization

- Languages like Blackfoot 


\section{Case studies of grammar in two Golding novels}

With this summary in mind I turn to the analysis of language in two novels of William Golding. I start with an outline of Halliday's seminal analysis of two linguist styles apparent in The Inheritors (Halliday 1973 [1971]) before comparing this with my own analysis of two similar stylistic contrasts in Pincher Martin.

\subsection{Halliday on The Inheritors}

The Inheritors is about the encounter between Neanderthals and Homo sapiens. Homo sapiens, like us, have technology - bows and arrows, daggers, sailboats religion, alcohol, clothes, complex sex, etc. Most of the novel is seen through the eyes of the Neanderthal Lok, who, gentle and generous, does not understand the behavior of the new people, especially their aggression. Homo sapiens brings about the death of all the members of the Neanderthal tribe except Lok and the baby, who they kidnap and adopt. The climax of the novel is when Lok discovers the burnt bones of his dead daughter, Liku, whom the Neanderthalers have sacrificed to appease their fear of Lok's tribe. Deprived of his tribe, Lok simply lies down and dies. At the end of the novel the Homo sapiens tribe with the baby sail upstream away from the Neanderthals they feared.

The novel can be read as an account of the fall of man from the simple and innocent Neanderthal to the complex, violent and technologically advanced Homo sapiens.

The style of the novel differs between Golding (1961 [1955]: 1-216) - Language A and Golding (1961 [1955]: 223-233) - Language C. In Language A we are seeing the world from the point of view or mindstyle of Lok the Neanderthal, while in Language $\mathrm{C}$ we are seeing the world from the point of view of the new people/ Homo sapiens and/or a human observer. Halliday took a representative extract from each section and analyzed the grammatical patterns or norms.

\section{Sample of Language A}

The bushes twitched again. Lok steadied by the tree and gazed. A head and chest faced him, half-hidden [...]. The man turned sideways in the bushes and looked at Lok along his shoulder. A stick rose upright and there was a lump of bone in the middle [...]. The stick began to grow shorter at both ends. Then it shot out to full length again.

The dead tree by Lok's ear acquired a voice.

"Clop!” 
His ears twitched and he turned to the tree. By his face there had grown a twig: a twig that smelt of other, and of goose, and of the bitter berries that Lok's stomach told him he must not eat [...]. He shouted at the green drifts across the glittering water and heard Liku crying out in answer but could not catch the words [...]. He rushed to the edge of the water and then rushed back. On either side of the open bank the bushes grew thickly in the flood; they waded out until at their farthest some of the leaves were opening under water; and these bushes leaned over [...]. He dashed at them where normally they would have been rooted on dry land and his feet splashed. He threw himself forward and grabbed at the branches with hands and feet. (Golding 1961 [1955]: 106-107)

Because these events are seen through the mind of Lok, it may be difficult for us, with the perspective and experience of Homo sapiens, to understand quite what is going on in the beginning of this passage. In fact a member of the Homo sapiens tribe is taking aim (looked at Lok along his shoulder), bending his bow (the stick grows shorter at both ends), firing an arrow at Lok, which misses and embeds itself in the tree by his head. The arrow has flights of goose feathers (smells of goose) and is poisoned (with the bitter berries that Lok's stomach told him he must not eat).

These are the grammatical patterns Halliday observed in Language A:

\section{Human actors are often in intransitive clauses, not affecting their environment}

Lok steadied by the tree

The man turned sideways in the bushes

He turned to the tree

He rushed to the edge of the water and then rushed back.

He dashed at them

He [threw himself forward and] grabbed at the branches with hands and feet

Parts of the body are frequently Actors (Sayers), rather than the whole person

His ears twitched

A head and chest faced him, half-hidden [...]

the bitter berries that Lok's stomach told him he must not eat

his feet splashed

\section{Actors are just as likely to be non-animate as animate}

The bushes twitched again.

A stick rose upright and there was a lump of bone in the middle [...].

The stick began to grow shorter at both ends. Then it shot out to full length again.

(In "normal" English this would be something like "Someone pulled the bow back")

The dead tree by Lok's ear acquired a voice. 
The bushes grew thickly in the flood; they waded out until at their farthest some of the leaves were opening under water; and these bushes leaned over

(Halliday 1973 [1971]: 126-128)

Note in these last examples that the animate/inanimate distinction is not made by Lok/the Neanderthals. Humans are part of the whole of animate nature, not separate or different or dominating.

As Halliday summarizes, this worldview is of people acting but not acting on things, moving themselves but not other objects, and in our terms is less than canonical. There is busy but ineffectual activity, and constant movement in which only the mover is affected. It is a mental world without cause and effect. Doing is as passive as seeing, things are no more affected by actions than by perceptions. People do not bring about events in which anything other than themselves or parts of their bodies are involved. This foregrounding of intransitivity reflects both the people's own actions and the people's world view (Halliday 1973 [1971]).

\section{Sample of Language $C$}

[...] As if they were obeying some signal the people began to stir, to sit up and look across the water at the green hills. Twal bent over Tanakil and kissed her and murmured to her. Tanakil's lips parted [...].

[...]

Now Vivani was really waking. They heard her huge luxurious yawn and the bear skin was thrown off. She stood up, shook back her loose hair and looked first at Marlan, then at Tuami. At once he was filled again with lust and hate. If she had been what she was, if she had saved her baby in the storm on the salt water -

[...]

The sand was swirling in Tuami's brain. He thought in panic: they have given me back a changed Tuami; what shall I do? Only Marlan is the same - smaller, weaker, but the same. He peered forward to find the changeless one as something he could hold on to. (Golding 1961 [1955]: 228-229)

By contrast with Language A, these are the grammatical patterns in Language C:

\section{The majority of the clauses (48/67) have a human subject.}

The people began to stir, to sit up and look across the water at the green hills.

Twal bent over Tanakil and kissed her and murmured to her.

Now Vivani was really waking.

They heard her huge luxurious yawn.

She stood up, shook back her loose hair and looked first at Marlan, then at Tuami.

If she had saved her baby in the storm on the salt water - [...]

He thought in panic: they have given me back a changed Tuami; what shall I do?

He peered forward to find the changeless one as something he could hold on to. 
Many of these are material actions, which are transitive with a Goal, with human agents acting on external objects/other people.

Twal kissed her

If she had saved her baby in the storm

They have given me back a changed Tuami

He peered forward to find the changeless one as something he could hold onto

(Halliday 1973 [1971]: 131-132)

Here we have the canonical cause and effect, with humans' actions extending beyond themselves and their own bodies to affect each other.

As already mentioned, this is a familiar world in which, elsewhere in the novel, Homo sapiens impinge on their environment with tools like axes, ropes, rollers, weapons such as bows and arrows, sail boats for transport, and clothes. It would seem that the technological revolution of Homo sapiens in the novel is the beginning of the process of dominating nature through technology taken to extremes in the last 250 years. This includes the industrial revolution, the manufacturing revolution of mass-produced production-line goods post first world war, and consumerism from the 1950s onwards in the West and from 2000s in China. The latest manifestations of technological domination include the potentially highly destructive nuclear technology and genetic engineering, as well as the industrialization of nature discussed above.

Homo sapiens's ability to act on his environment and other people is frightening. It is often put to misuse even in the novel in magic, witchcraft, drunken sexual orgies, religious oppression and pre-meditated murder, though it also manifests itself as artistic endeavor, when Tuami carves the handle of a dagger, seen as just as important as the blade.

The story is about the Fall of Man, where we dominate nature and other people rather than living in harmony with them. The comparison with Daoism is instructive. Neanderthalers exemplify wu-wei. One might note that classical Daoism developed during the Warring States period, possibly partly as a reaction against the use of technology for war. Perhaps they share an ideology and ontology, though I am not expert enough on Daosim or Chinese history to explore this connection.

\subsection{Stylistic/Buddhist analysis of Pincher Martin}

Several years ago, inspired by Halliday's analysis of the grammar of The Inheritors I performed a similar but rather more detailed analysis of another Golding novel, Pincher Martin, relating it to Buddhism but not Daosim (Goatly 1996). I summarize 
some of my findings here, relating them to Daosim and scientific theory perhaps more thoroughly than in the original monograph.

Pincher Martin tells the story of Christopher Hadley (Pincher) Martin, a Second World War naval officer, who drowns in the sea after his ship is torpedoed. He drowns somewhere between pages 8 and 10 of the novel. The next 190 pages are Pincher's imagination of his own six-days survival, in which he kicks off his seaboots (Golding 1956: 10), swims to an isolated rocky island, builds a rescue beacon out of boulders to signal to ships or aircraft, lives off shellfish, pretends madness as he is attacked by black lightning which finally reduces him to a pair of selfclutching lobster claws, while around him his imaginary island disintegrates. In the last chapter, beginning on page 202, his body, with feet still in seaboots, is picked up from a Scottish island where it has been washed ashore.

Unlike the structure of The Inheritors there is not such a clear change between styles, reflecting the mind style of Neanderthals and those of a detached human observer. However, an obvious division is between the language of the passage describing the reality of Pincher drowning, Passage A, and later passages which describe the illusion of survival, from which I have selected the description of Pincher building the rescue beacon. Passage A is from Golding (1956: 13) "His voice died and his face untwisted.” to Golding (1956: 23) "He lay still.” (2,957 words). Passage B is from Golding (1956: 58) "As in the sea at a moment of desperate crisis his body changed, became able and willing." to Golding (1956: 67) “A gull moved a little then settled down again.” (3,063 words).

\section{Extract from Passage $A$}

There were hands to be sure and two forearms of black oilskin and there was the noise of breathing, gasping (1). There was also the noise of the idiot stuff, whispering, folding on itself, tripped ripples running tinkling by the ear like miniatures of surf on a flat beach (2); there were sudden hisses and spats, roars and incompleted syllables and the soft friction of wind (3). The hands were important under the bright side of the circle but they had nothing to seize on (4). There was an infinite drop of the soft, cold stuff below them and under the labouring, dying, body (5).

The sense of depth caught him and he drew his dead feet up to his belly as if to detach them from the whole ocean (6). He arched and gaped, he rose over the chasm of deep sea on a swell and his mouth opened to scream against the brightness (7).

It stayed open (8). Then it shut with a snap of teeth and his arms began to heave water out of the way (9). He fought his way forward (10).

“Ahoy - for Christ's sake! Survivor! Survivor! Fine on your starboard bow!” (11)

He threshed with his arms and legs into a clumsy crawl (12). A crest overtook him and he jerked himself to the chest out of water (13). (Golding 1956: 19) 
The following grammatical patterns are prominent.

\section{Nominalization of qualities and processes:}

Depth, brightness, breathing, gasping, ripples, hisses, roars, drop, sense, swell, snap, crawl.

Often these nominalizations are in existential clauses:

There was the noise of breathing, gasping. (1)

There were sudden hisses and spats, roars. (3)

Sometimes these nominalizations are actors

The sense of depth caught him. (6)

Most clauses (with Pincher or his body-part as Actors) are intransitive and superventive i.e. involuntary beyond his control

He arched and gaped, he rose over the chasm of deep sea on a swell and his mouth opened to scream against the brightness. (7)

He threshed with his arms and legs into a clumsy crawl. (12)

Exceptions are when

he is acting on himself

He jerked himself to the chest out of water. (13)

He drew his dead feet up to his belly. (6)

they are pseudo-effective (no Goal/Affected)

He fought his way forward. (10)

the actor is a body part

His arms began to heave water out of the way. (9)

These nominalizations construct a world of process and interacting processes, quite in step with the insights of modern physics and Buddhism/Daoism, as discussed in Section 2.

It is also worth noting that the preponderance of general non-specific words (e.g. "noise," "stuff”) and shape/dimension words (e.g. "line," "circle," "depth"). These are the vestiges of sensations that Pincher holds onto in order to begin the 
process of differentiation, classification, inimical to Daoism/Buddhism, by which he goes on to create an unreal world. Another strategy for fabricating the illusory world for survival is the use of nominalized adjectives. The adjective "bright" (4) is nominalized to "brightness" (7), which later is used to fabricate the illusion of bright things and vision in his fantasy survival. He similarly uses the nominalizations "whiteness" and "hardness" though these do not appear in the extract (Goatly 1996).

\section{Extract from Passage B}

There was a broken rock below his hands, leaning against the wall from which the clean fracture had fallen (14). He climbed down and wrestled with a great weight (15). He made the stone rise on an angle; he quivered and the stone fell over (16). He collapsed and lay for a while (17). He left the stone and scrambled heavily down to the little cliff and the scattered rocks where he had bathed his eye (18). He found an encrusted boulder lying in a rock pool and pulled it up (19). He got the stone against his stomach, staggered for a few steps, dropped the stone, lifted and carried again (20). He dumped the stone on the high point above the funnel and came back (21). There was a stone like a suitcase balanced on the wall of a trench and he pondered what he should do (22). He put his back against the suitcase and his feet against the other side of the trench (23). The suitcase grated, moved (24). He got a shoulder under one end and heaved (25). The suitcase tumbled in the next trench and broke (26). He grinned without humour and lugged the larger part up into his lap (27). He raised the broken suitcase to the wall, turned it end over end, engineered it up slopes of fallen but unmanageable rock, pulled and hauled (28).

Then there were two rocks on the high part, one with a trace of blood (29). He looked once round the horizon and climbed down the slope again (30). He stopped, put a hand to his forehead, then examined the palm (31). But there was no blood (32). (Golding 1956: 61)

The contrast in grammar with the extract from Passage A is obvious.

\section{There is only one nominalization}

He climbed down and wrestled with a great weight. (15)

We can note in this example how the abstract sensation weight has been fabricated into a rock - an example of differentiation using sensation in Buddhist terms.

\section{Existential clauses do not have nominalizations as existents}

There was a broken rock below his hands. (14)

There was a stone like a suitcase balanced on the wall of a trench. (22)

Then there were two rocks on the high part, one with a trace of blood. (29) 
Most intransitive clauses with Pincher as Actor are non-superventive, i.e. voluntary

He climbed down and wrestled with a great weight. (15)

He came back. (12)

He [...] scrambled heavily down to the little cliff. (18)

He looked once round the horizon and climbed down the slope again. (30)

He stopped [...] (31)

\section{Many clauses are transitive material processes, also non-superventive}

He made the stone rise on an angle; (16)

He left the stone [...] he had bathed his eye. (18)

He found an encrusted boulder lying in a rock pool and pulled it up. (19)

He got the stone against his stomach, [...] dropped the stone [...] (20)

He dumped the stone. (21)

He put his back against the suitcase and his feet against the other side of the trench. (23)

He got a shoulder under one end and heaved. (25)

He [...] lugged the larger part up into his lap. (27)

He raised the broken suitcase to the wall, turned it end over end, engineered it [...] (28)

He [...] put a hand to his forehead, then examined the palm. (31)

How can we interpret the differences between the two passages? In the extract from Passage A Pincher inhabits a world of processes, conveyed by nominalizations, which exist independent of him, some of which act upon him. He has not established the voluntary will to govern his own actions/body parts, samskara ('voluntary action'). He seldom manages to affect his environment materially. In the extract from Passage B Pincher inhabits a world where things exist rather than processes. It is a world where he has control of voluntary actions, and he is able to affect changes to his environment (by moving rocks). His will to voluntary action, samskara, has been established and implemented.

We can take our analysis further by quantifying grammatical structures in the whole of Passages A and B (Tables 2-4). Most of the data here is self-explanatory, but some aspects need elaboration.

In Table 2 we quantify the use of the pseudo-effective structure. It occurs when a nominalized Range or its equivalent is used as the Object/Goal, e.g. He began to make swimming motions. In Passage A there are 7 examples, in Passage B, 2. They often use the formula: make swimming movements/motions, where the movements are made, or made up, by the mind:

His mind inside the dark skull made swimming movements long after the body lay motionless in the water. (Golding 1956: 16) 
Table 2: Comparing the material clause grammar of Passages $A$ and $B$ according to the transitivity system.

\begin{tabular}{lrr}
\hline & Passage A & Passage B \\
\hline Non-ergative (transitive) clauses & 183 & 275 \\
Intransitive or middle & 79 & 127 \\
\hline Pincher non-superventive & 21 & 66 \\
Pincher superventive & 24 & 10 \\
$\quad$ Body parts superventive & 9 & 17 \\
Pseudo-effective (range) & 7 & 2 \\
\hline Transitive or effective & 104 & 148 \\
Active & & \\
With Pincher as Actor (non-reflexive) & 11 & 80 \\
With sea as Actor, Pincher as Goal & 12 & 0 \\
Passive & 25 & 23 \\
Pincher as Goal & 17 & 4 \\
\hline
\end{tabular}

Table 3: Comparing the material clause grammar of Passages A and B according to the ergativity system.

\begin{tabular}{lrr}
\hline & Passage A & Passage B \\
\hline Ergative clauses & 34 & 49 \\
Ergative effective & 7 & 19 \\
$\quad$ Instigator & & 16 \\
$\begin{array}{l}\text { Pincher } \\
\text { Medium }\end{array}$ & 2 & 15 \\
Inanimate (rock) & 0 & \\
\hline
\end{tabular}

Table 4: Some general grammatical patterns in Passages A and B.

\begin{tabular}{lrr}
\hline PINCHER AS ACTOR/INSTIGATOR IN EFFECTIVE & 13 & 96 \\
(NON-ERGATIVE + ERGATIVE) CLAUSES & & \\
Body-parts (body) as subject in material processes & 20 & 19 \\
Nominalizations as subject & 24 & 11 \\
\hline \multicolumn{1}{c}{ Middle } & 7 & 9 \\
Effective & 17 & 2 \\
\hline
\end{tabular}


But Pincher soon ignores the mental origins of his swimming:

He made swimming movements again without thought [...]. (Golding 1956: 18)

We may contrast this with:

He thought movements that did not happen. The sea came back and he thought the movements again and this time they happened because the sea took most of his weight. (Golding 1956: 22)

This phenomenon seems to be a grammatical and lexical realization of the effect of vijnana ('consciousness'), one stage of the twelve in Dependent Origination: it is consciousness which survives the death of the body and assumes a new existence by being inseparably connected with (or finding new support in) a different body.

Without going into too much detail, it is worth drawing attention to 4 aspects of this quantitative data. First, Table 4 indicates the clear contrast in the power of Pincher over nature. Pincher and his body parts are Actor/Instigator only 13 times in Passage A, but 96 times in Passage B. Conversely, Pincher is a Goal in passive clauses 17 times in Passage A and only 4 in Passage B, and a Goal with sea as actor 12 times in Passage A (Table 2). This sums up his transformation from passivity at the mercy of the sea to striving for dominance over the environment, in his moving of rocks (Table 3). Second, grammatical patterns also highlight the emergence of samskara. Compare the numbers of non-superventive, voluntary actions and superventive involuntary actions in Table 2, Passage A has 21 non-superventive and Passage $B$ 66, while there is a reverse pattern for superventive, 24 superventive in Passage A and 10 in Passage B. Third, in Passage A, Pincher often goes with the "grain" of wu-wei, as Daoism puts it. Literally he goes with the flow of natural processes as a Goal with the sea as Actor (Table 2).

Fourth, there are a large number of nominalizations as subjects/actors (Table 4). Pincher often acts on himself at one remove: e.g. he will make an action, experience a feeling or a thought, and subsequently this action or experience will act on him (karma):

[...] [the snarl] worked on the wooden face

[...] and his movements broke up the stony weight of his legs.

$[\ldots]$ and the thought drove him to foam in the water - (vijnana 'consciousness')

[...] The first, fierce excitement of sighting had burned up the fuel

[...] The force of his return sent him under

[...] The little warmth of anger flushed blood back into the tops of the cheeks (vedana 'feeling')

I have suggested how some of these quotations might be related to Buddhist concepts, in parentheses. 


\subsection{Comparisons: Pincher Martin, The Inheritors, Transitivity, and Buddhism/Daoism}

Let's now bring together Halliday's and my analysis, in relation to the Daoist concept of wu-wei. We may compare the intransitive clause world of Passage A and the transitive world of Passage B with Halliday's intransitive clause world of Lok in Language A and the transitive world of agentive Homo sapiens in Language C (See also Black 1993: 47). Because the different languages and grammars not only convey a worldview, mind-style, but also behavior, life-style we can map this contrast onto the distinction between excessive voluntary action and its opposite, wu-wei, as in Figure 5:

THE INHERITORS

LANGUAGE A : LANGUAGE C

WU-WEI EXCESSIVE ACTION
PINCHER MARTIN

LANGUAGE OF PASSAGE A: LANGUAGE OF PASSAGE B

$W U-W E I$

EXCESSIVE ACTION

Note: ":" means "is to" and "::" means "as", to express an analogical relationship - A is to C as A is to B

Figure 5: Halliday and Goatly's analyses of contrasting grammar in relation to wu-wei.

There is a further similarity. Both with Lok in Language A and the drowning Pincher of Passage A, body parts have an autonomous life (Golding 1956: 10 above and Table 2), and are seldom brought under the control of an organizing purposeful volitional consciousness (vijnana) (Goatly 1987).

The relation to Buddhism can also be discerned, and this summary of the unsatisfactoriness of human existence by a Buddhist scholar could well sum up a main theme of the novel Pincher Martin:

By ignorance the being fails to view the true impermanent and substanceless nature of existence. He relishes the things of the world, taking them to be real and lasting and creates a craving for them. Due to his cravings, he grasps to attain one and avoid the other. This leads to the continuity of his life process, a chain of struggle for living. His cravings and graspings do not end with the destruction of his physical frame, but they keep the struggle on in another birth. (Kashyap 1954: 212)

\section{Summary: Language, languages, science, and Buddhism/Daoism}

We can finally summarize the argument of this article as follows. Dynamic processes are the ultimate quantum and ecological reality. These processes 
interpenetrate in a material universe of undivided wholeness. Permanence is a myth. Control over nature is also a dangerous myth, exemplified in the language of The Inheritors (Language C) and Pincher Martin (Language of Passage B). English and other [European] languages are generally inadequate for representing these truths, though nominalization might be able to emphasize process. Other languages such as Blackfoot, where nouns are scarce and processes are emphasized, are better at representing the Buddhist-Daoist/quantum physics/ecological worldview.

We might end with the sobering thought that just as we are destroying our world and its biodiversity, so we are simultaneously endangering languages such as Blackfoot.

\section{References}

Black, Elizabeth. 1993. Metaphor, simile and cognition in Golding's The Inheritors. Language and Literature 2(1). 37-48.

Bohm, David. 1980. Wholeness and the implicate order. London: Routledge.

Bohm, David \& Basil J. Hiley. 1975. On the intuitive understanding of nonlocality as implied by quantum theory. Foundations of Physics 5(1). 93-109.

Capra, Fritjof. 1982. The Tao of physics: An exploration of the parallels between modern physics and eastern mysticism. London: Flamingo.

Chuang Tzu. 1964. Chuang Tzu: Basic writings. Watson Burton (trans.). New York: Columbia University Press.

Eggins, Suzanne, Peter Wignell \& James Robert Martin. 1993. The discourse of history: Distancing the recoverable past. In Mohsen Ghadessy (ed.), Register analysis: Theory and practice, 75-109. London: Pinter.

Goatly, Andrew. 1987. Interrelations of metaphors in Golding's novels: A framework for the study of metaphoric interplay. Language and Style 20(2). 125-144.

Goatly, Andrew. 1996. Buddhist lexicogrammar in Golding's Pincher Martin. Singapore: Department of Language and Literature, National University of Singapore.

Goatly, Andrew. 2007. Washing the brain: Metaphor and hidden ideology. Amsterdam: Benjamins.

Golding, William. 1956. Pincher Martin. London: Faber.

Golding, William. 1961 [1955]. The inheritors. London: Faber.

Greenblatt, Stephen \& Meyer Howard Abrams. 2006. The Norton anthology of English literature, vol. 2, 8th edn. New York \& London: W. W. Norton \& Company.

Halliday, Michael Alexander Kirkwood. 1973 [1971]. Linguistic function and literary style: An inquiry into William Golding's The Inheritors. In Michael Alexander Kirkwood Halliday (ed.), Explorations in the function of language, 103-140. London: Arnold.

Halliday, Michael Alexander Kirkwood. 1993. On the language of physical science. In Mohsen Ghadessy (ed.), Register analysis: Theory and practice, 162-178. London: Pinter. Josephson, Paul R. 2002. Industrialized nature: Brute-force technology and the transformation of the natural world. London: Shearwater Books. 
Kalupahana, David J. 1975. Causality: The central philosophy of Buddhism. Honolulu: University Press of Hawaii.

Kashyap, Bhikkhu J. 1954. The Abhidhamma philosophy. Nalanda: Bauddha Vihara.

Kohn, Livia. 2009. Introducing Daoism. Abingdon: Routledge.

Komjathy, Louis. 2014. Daoism: A guide for the perplexed. London: Bloomsbury.

Lafargue, Michael. 1992. The Tao of the Tao Te Ching: A translation and commentary. Albany: State University of New York Press.

Langacker, Ronald W. 1991. Foundations of cognitive grammar, vol. II: Descriptive application. Stanford: Stanford University Press.

Little Bear, Leroy \& Ryan Heavy Head. 2004. A conceptual anatomy of the Blackfoot word. ReVision: A Journal of Consciousness and Transformation 26(3). 31-38.

Lovelock, James. 1988. The ages of Gaia: A biography of our living earth. Oxford: OUP.

Peat, David F. 1996. Blackfoot physics: A journey into the native American universe. London: Fourth Estate. 